\title{
Um estudo relativo ao processo histórico das Cooperativas de Eletrificação: O caso do Brasil e Estados Unidos
}

\author{
Relative to the historical process of Cooperatives Electrification study: the case of \\ Brazil and the United States
}

\begin{abstract}
Resumo
O presente estudo teve por objetivo descrever os principais aspectos relativos ao processo histórico das Cooperativas de eletrificação (CEs) brasileiras em relação às CEs americanas. Trata-se de uma pesquisa qualitativa, do tipo exploratória, realizada sob a forma de pesquisa bibliográfica, com dados obtidos por meio de material publicado em livros, revistas, teses e dissertações e na rede mundial de computadores. Os resultados demonstram que a inexistência de políticas de eletrificação de longo prazo com foco nas CEs, não proporcionou o crescimento do setor, no Brasil. Assim, o modelo de eletrificação rural por meio das CEs, desenvolveu-se de forma enviesado com as concessionárias públicas. A indefinição de competências, a insegurança jurídica, no que se refere as regras do setor, a competição por áreas de atendimento de energia com as grandes concessionárias, antes públicas e agora privatizadas, o tratamento de forma igual às grandes concessionárias, são alguns dos pontos que ainda perduram até os dias atuais. Por outro lado, o crescimento do setor rural americano deu-se prioritariamente pela entrada de energia elétrica na década de 1930. O programa de incentivo governamental, alocados em investimento na eletrificação foi o motor que acelerou a expansão e a consolidação da eletrificação rural dos estados americanos.
\end{abstract}

Palavras-chave: Cooperativas de eletrificação, Brasil, Estados Unidos.

\begin{abstract}
This study aimed to describe the main aspects of the historical process of electrification cooperatives (ECs) Brazilian in relation to American ECs. It is a qualitative research, exploratory, held in the form of literature, with data obtained through material published in books, magazines, theses and dissertations and the World Wide Web. The results show that the long-term electrification policies of absence to focus on CEs did not provide the growth of the sector in Brazil. Thus, the model of rural electrification through the ECs, developed in a biased manner with public utilities. The blurring of responsibilities, the legal uncertainty regarding the rules of the industry, competition for energy service areas with large dealerships, before public and now privatized, treatment equally to large utilities, are some of the points that still linger to this day. On the other hand, the growth of the American rural sector was given priority by the electrical power input in the 1930s the government incentive program, allocated to investment in electrification was the engine that accelerated the expansion and consolidation of rural electrification states Americans.that accelerated the expansion and consolidation of rural electrification states Americans.
\end{abstract}

Keywords: Rural electrification cooperatives, Brazil, United States.

Recebido: 25/02/2015 Aceito: 13/07/2015

Lorimar Francisco Munaretto ${ }^{1}$

${ }^{1}$ Universidade Federal de Santa Maria, Doutorado em administração - franciscomunaretto@gmail.com 


\section{Introdução}

$\mathrm{A}$ s sociedades cooperativas se distinguem pela prestação de serviços aos seus associados. Pois são constituídas e representadas pelos associados (número de sócios) independentemente da participação no capital da cooperativa e pela natureza (foco) em relação aos aspectos sociais e econômicos, de seus associados. Nas cooperativas o cooperado é dono e usuário da cooperativa.

As Cooperativas de Eletrificação (CEs) surgiram no Brasil, em sua maior parte nas décadas de 1960 e 1970, tendo em vista a geração e a distribuição de energia elétrica. Na região Sul e Sudeste, as CEs surgiram pelo esforço comunitário e associativo em áreas rurais distantes dos centros, primordialmente pelo desinteresse das concessionárias públicas em realizar investimentos nestes locais. Já no Nordeste do Brasil, as CEs foram criadas pelas Concessionárias, com o objetivo de servir como agentes de canalização de recursos em programas de eletrificação rural.

Situação dessemelhante ocorreu na eletrificação rural dos Estados Unidos (EUA), onde às CEs foram criadas em sua maioria na década de 1930, por estímulo do governo federal por meio de um programa de eletrificação rural, com financiamentos subsidiados.

No Brasil, a falta de políticas governamentais de eletrificação rural, direcionadas ás CEs, a indefinição de áreas e competências de trabalho e a falta de reconhecimento das CEs, são os principais motivos de conflitos com as concessionárias que persistem até os dias atuais.

O presente estudo tem por objetivo descrever os principais aspectos relativos ao processo histórico das CEs brasileiras em relação às CEs americanas.

O estudo apresenta além da introdução, no capítulo 2 a revisão da literatura, no capítulo 3 a metodologia do trabalho, no capítulo 4 os resultados e por fim as conclusões.

\section{Revisão de literatura}

Na sequência apresenta-se a revisão teórica do presente estudo. O capítulo inicia abordando sobre o surgimento das cooperativas e seus princípios norteadores, na segunda seção apresenta o cooperativismo no Brasil, após descreve-se sobre as Cooperativas de eletrificação e por fim sobre as cooperativas de eletrificação nos Estados Unidos.

\subsection{Surgimento das cooperativas e seus prin- cípios}

As cooperativas surgiram com a revolução industrial. $\mathrm{O}$ excesso de mão de obra, o desemprego acentuado e a busca por melhores condições de vida da época, foram alguns motivos que proporcionaram a criação de uma sociedade por meio dos tecelões Ingleses. Assim surge a primeira cooperativa que foi formada por 28 tecelões ingleses, por meio de um armazém comunitário na Travessa do Sapo ("Toad Lane"), no Bairro Rochdale, em Manchester, na Inglaterra. Por meio deste armazém que oferecia, no início, aos seus associados, manteiga, açúcar, farinha de trigo, aveia etc., em 21 de dezembro de 1844, foi criada a "Sociedade dos Probos Pioneiros de Rochdale", que é caracterizada como o marco do "nascimento oficial do cooperativismo" (PINHO, 1966).

Os 28 (vinte e oito) sócios Pioneiros de Rochdale, na época conceberam 7 (sete) princípios que formam a base filosófica que regem as cooperativas, que são: adesão livre, gestão democrática, juros módicos ao capital, retorno proporcional às operações, transações a dinheiro, neutralidade política, religiosa e étnica e desenvolvimento do ensino em todos os seus graus (PINHO, 1966).

De acordo com Pinho (1995) os princípios que foram desenvolvidos pelos pioneiros da Rochdale, na sua fundação, foram redefinidos no ano de 1995, por meio da International Cooperative Alliance (ACI), órgão de representação mundial do cooperativismo com sede em Genebra na Suíça e são os seguintes:

$1^{\circ}$ - Adesão voluntária e Livre (Aberta): as cooperativas são organizações voluntárias, abertas a todas as pessoas aptas a utilizar os seus serviços e assumir as responsabilidades como membros, sem discriminações de sexo, sociais, raciais, políticas e religiosas.

$2^{\circ}$ - Gestão (controle) democrática dos membros: as cooperativas são organizações democráticas, controladas pelos seus membros, que participam ativamente na formulação das suas políticas e na tomada de decisões. 
$3^{\text {o }}$ - Participação econômica dos membros: os membros contribuem equitativamente, para o capital das suas cooperativas e controlam-no democraticamente. Parte desse capital é, normalmente, propriedade comum da cooperativa. Os membros recebem, habitualmente, se houver, uma remuneração limitada ao capital integralizado, como condição de sua adesão. Os membros destinam os excedentes a uma ou mais das seguintes finalidades:

i) desenvolvimento das suas cooperativas, eventualmente por meio da criação de reservas, parte das quais, pelo menos, será indivisível; ii) benefícios aos membros na proporção das suas transações com a cooperativa; e iii) apoio a outras atividades aprovadas pelos membros.

$4^{\circ}$ - Autonomia e independência: as cooperativas são organizações autônomas, de ajuda mútua, controladas pelos seus membros. Se firmarem acordos com outras organizações, incluindo instituições públicas, ou recorrerem a capital externo, devem fazê-lo em condições que assegurem o controle democrático pelos seus membros e mantenham a autonomia da cooperativa.

$5^{\circ}$ - Educação, formação (treinamento) e informação: as cooperativas promovem a educação e a formação dos seus membros, dos representantes eleitos e dos trabalhadores, de forma que estes possam contribuir, eficazmente, para o desenvolvimento das suas cooperativas.
$6^{0}$ - Intercooperação: as cooperativas servem de forma mais eficaz aos seus membros e dão mais força ao movimento cooperativo, trabalhando em conjunto, por meio das estruturas locais, regionais, nacionais e internacionais.

$7^{\circ}$ - Interesse (preocupação) pela comunidade: as cooperativas trabalham para o desenvolvimento sustentado das suas comunidades por meio de políticas aprovadas pelos membros.

A adoção das práticas cooperativistas (princípios cooperativistas) levam as cooperativas a se diferenciarem das empresas tradicionais. Segundo Etgeto et al (2005, p.12), "nas cooperativas todos são, ao mesmo tempo, sócios, fornecedores, clientes e, às vezes, empregados, e isto, independente da modalidade de cooperativa (...)." Enquanto que em uma empresa tradicional o poder está determinado pelo capital por meio do número de ações de cada um dos sócios, nas cooperativas a cada sócio corresponde um voto, independentemente do capital por ele aportado à empresa. O quadro a seguir apresenta as principais diferenças entre sociedades cooperativas e demais sociedades que possuem, como finalidade, lucro.

Quadro 1 - Principais diferenças entre sociedades cooperativas de demais sociedades

\begin{tabular}{|l|l|}
\hline \multicolumn{1}{|c|}{ Empresa Cooperativa } & \multicolumn{1}{c|}{ Empresa não Cooperativa } \\
\hline É uma sociedade de pessoas & É uma sociedade de capital \\
\hline $\begin{array}{l}\text { Objetivo principal é a prestação de } \\
\text { serviço (sobras) }\end{array}$ & Objetivo principal é o lucro \\
\hline Número ilimitado de associados (Adesão livre) & Número limitado de acionistas \\
\hline Controle democrático: Um homem, um voto & Cada ação = um voto \\
\hline $\begin{array}{l}\text { Assembleia: “quórum” com base no número de associ- } \\
\text { ados }\end{array}$ & Assembleia: “quórum” com base no capital \\
\hline $\begin{array}{l}\text { Não é permitida a transferência das quotas-partes a a } \\
\text { terceiros, estranhos à sociedade. }\end{array}$ & Transferências das ações a terceiro são permitidas \\
\hline $\begin{array}{l}\text { Retorno proporcional ao valor das operações (Retorno } \\
\text { aos associados) }\end{array}$ & $\begin{array}{l}\text { Dividendo proporcional ao valor das ações (Retor- } \\
\text { no aos investidores) }\end{array}$ \\
\hline
\end{tabular}

Fonte: PINHO (1966, p.53)

Pinho (1966, p.53) explica que além dessas diferenças, "as cooperativas desempenham um papel educativo e social, o que não se dá, de modo geral, com as demais empresas comerciais." Essas são algumas das características das cooperativas e que as diferenciam das demais empresas não cooperativas.

\subsection{Cooperativismo no Brasil}

A experiência de Rochdale possibilitou a expansão e constituição de diversas cooperativas pelo mundo. No Brasil, o movimento cooperativo começou a se formar no ano de 1847, três anos após a fundação da Rochdale na Inglaterra, por meio do médico Francês, Joean Maurice Faivre, simpatizante das ideias de Charles Fourier, fundou com um grupo de europeus nos sertões do Paraná, a colônia 
Tereza Cristina, organizada em bases cooperativas. Essa organização, apesar de sua breve existência, contribuiu na memória coletiva como elemento formador do cooperativismo brasileiro (OCESP, 2015).

De acordo com Pelegrini (2003, p.12) no Brasil os "movimentos cooperativistas surgiram com diferentes propósitos, como de consumo, de crédito, de pesca, habitacionais, educacionais, agropecuárias, de saúde, de trabalho, de eletrificação rural etc."

As primeiras cooperativas que surgiram no Brasil foram do setor do consumo. De acordo com ETGETO et al. (2005), em 1887 surgiu a Cooperativa de Consumo dos Empregados da Companhia Paulista, na cidade de Campinas (SP). Dois anos depois, em Ouro Preto (MG), foi criada uma Sociedade Econômica Cooperativa. De acordo com Pinho (1996, p.96), em 1891, na cidade de Limeira (SP), foi fundada a Cooperativa dos Empregados da Companhia Telefônica, no Rio de Janeiro, então
Distrito Federal (na época), surgiu a Cooperativa Militar de Consumo, no ano de 1894. No ano de 1895, foi constituída a Cooperativa de Consumo de Camaragibe, em Pernambuco.

No ano de 1902, colonos de origem Alemã, incentivados pelo padre Jesuíta Theodor Amstad, fundaram uma Cooperativa de crédito rural (Caixa Rural Raiffeisen no RS), na Vila Império, atualmente Nova Petrópolis/RS, que é a mais antiga Cooperativa em atividade no País.

As características de gestão, alicerçada aos princípios doutrinários, impulsionou o crescimento do cooperativismo. De acordo com a Organização das Cooperativas do Brasil (OCB), no mundo, o movimento cooperativo reúne mais de 1 bilhão de pessoas. No Brasil, no final do ano de 2013, o número de cooperativas era de 6827, classificadas em 13 (treze) ramos de atuação, com quadro social de 11.563.427 de associados e contemplando 337.793 empregados (SESCOOP/OCB; 2014).

Quadro 2 - Ramo de atividade, número de cooperativas, número de associados e número de empregados das cooperativas existentes em 31/12/2013.

\begin{tabular}{|l|r|r|r|r|r|r|}
\hline Ramo de Atividade & $\mathbf{n}^{\mathbf{0}}$ Cooperativas & \multicolumn{1}{c|}{$\boldsymbol{\%}$} & $\mathbf{n}^{\mathbf{0}}$ Ass ociados & \multicolumn{1}{c|}{$\boldsymbol{\text { \% }}$} & $\mathbf{n}^{\mathbf{0}}$ Empregados & \% \\
\hline Agropecuário & 1.597 & $23,39 \%$ & 1.007 .675 & $8,71 \%$ & 161.701 & $47,87 \%$ \\
\hline Consumo & 122 & $1,79 \%$ & 2.923 .221 & $25,28 \%$ & 13.880 & $4,11 \%$ \\
\hline Crédito & 1.034 & $15,15 \%$ & 5.808 .064 & $50,23 \%$ & 41.199 & $12,20 \%$ \\
\hline Educacional & 300 & $4,39 \%$ & 52.371 & $0,45 \%$ & 4.079 & $1,21 \%$ \\
\hline Especial & 6 & $0,09 \%$ & 247 & $0,00 \%$ & 7 & $0,00 \%$ \\
\hline Habitacional & 220 & $3,22 \%$ & 120.520 & $1,04 \%$ & 1.035 & $0,31 \%$ \\
\hline Infraestrutura & 130 & $1,90 \%$ & 934.892 & $8,08 \%$ & 6.496 & $1,92 \%$ \\
\hline Mineral & 86 & $1,26 \%$ & 87.152 & $0,75 \%$ & 180 & $0,05 \%$ \\
\hline Produção & 253 & $3,71 \%$ & 11.527 & $0,10 \%$ & 3.386 & $1,00 \%$ \\
\hline Saúde & 849 & $12,44 \%$ & 249.906 & $2,16 \%$ & 92.198 & $27,29 \%$ \\
\hline Trabalho & 977 & $14,31 \%$ & 228.613 & $1,98 \%$ & 1.929 & $0,57 \%$ \\
\hline Transporte & 1.228 & $17,99 \%$ & 137.543 & $1,19 \%$ & 11.685 & $3,46 \%$ \\
\hline Turismo e Lazer & 25 & $0,37 \%$ & 1.696 & $0,02 \%$ & 18 & $0,01 \%$ \\
\hline TOTAL & $\mathbf{6 . 8 2 7}$ & $\mathbf{1 0 0} \%$ & $\mathbf{1 1 . 5 6 3 . 4 2 7}$ & $\mathbf{1 0 0 \%}$ & $\mathbf{3 3 7 . 7 9 3}$ & $\mathbf{1 0 0 \%}$ \\
\hline
\end{tabular}

Fonte: Adaptado do Relatório da Gerência de Monitoramento - SESCOOP/OCB - Março 2014 - "Panorama do Cooperativismo Brasileiro - ano 2013".

No Brasil, o ramo cooperativo, com maior número de cooperativas, é o do setor agropecuário, seguido das cooperativas de transporte, de crédito e de trabalho. Em relação ao número de associados à cooperativa que possui a maior quantidade de sócios é a do setor de crédito, seguida do setor de consumo, do agropecuário e de infraestrutura. Quanto à empregabilidade a cooperativa do setor agropecuário é a que emprega mais, seguida da cooperativa da saúde, do setor de crédito e de consumo. Estes 13 (treze) ramos de cooperativas são responsáveis por $6 \%$ do Produto Interno Bruto (PIB), totalizando $\mathrm{R} \$$ 72,2 bilhões de faturamento, sendo que, deste total, 
$\mathrm{R}$ \$ 60 milhões foram gerados pelo ramo agropecuário (OCB, 2011).

Entre os treze ramos de cooperativas, as cooperativas de eletrificação (CEs) além das cooperativas de telefonia rural são classificadas dentro do grupo de infraestrutura, cuja finalidade é atender direta e, prioritariamente, o próprio quadro social com serviços de energia e telefonia. As CEs têm por objetivo fornecer, para a comunidade, serviços de energia elétrica, repassando essa energia de concessionárias e gerando sua própria energia (OCB, 2012).

\subsection{Cooperativas de eletrificação (CEs) no Brasil}

O primeiro registro do uso de energia elétrica na zona rural no Brasil foi no ano de 1923, quando João Nogueira de Carvalho instalou eletricidade em sua propriedade no município de Batatais - São Paulo/SP (FECOERGS, 2011).

As primeiras CEs surgiram no Estado do RS, no início da década de 1940, primeiramente, por iniciativa de pequenos núcleos urbanos, que pretendiam eletrificar suas residências; posteriormente às cooperativas foram expandindo suas áreas de atuação, englobando ou atingindo também a área rural (FUGIMOTO, 2005).

A Cooperativa Força e Luz de Quatro Irmãos, no distrito de José Bonifácio, no município de Erechim - RS, criada no ano de 1941, foi a primeira cooperativa de eletrificação rural, e tinha por objetivo gerar e distribuir energia para a pequena localidade, sede de uma companhia colonizadora da região, que ali se instalou em 1911, a Jewish Colonization and association (FECOERGS, 2012). Seu primeiro presidente foi o Sr. Alberto Verminghoff, com outros 22 associados, fundaram a cooperativa para levar energia elétrica até a sede da comunidade de Quatro Irmãos (SIMON, 2011).

De acordo com Rosset et al. (2009), a falta de interesse das companhias de energia na distribuição de energia elétrica, em áreas rurais distantes dos centros, foi motivo que despertou a criação e organização de CE rural, visando à geração e à distribuição de energia elétrica aos seus associados.

Pasin (2013) explica que as cooperativas de eletrificação surgiram e se desenvolveram na limitação das concessionárias em investir na área rural, o que levou o Governo Federal a proporcionar, na década dos anos 70, financiamentos do BID - Banco Inte- ramericano de Desenvolvimento, exclusivos para cooperativas de eletrificação rural, repassados através do GEER -Grupo Executivo de Eletrificação Rural (MAPA).

As propriedades rurais isoladas e pequenos povoados, constituídos de pequenos e médios agricultores, passaram a fundar as cooperativas, construir as redes de energia elétrica, passaram também a mantê-las, operá-las e expandi-las, criando assim sistemas isolados de distribuição de energia elétrica, no meio rural (PASIN,2013).

Nas regiões sul e sudeste, as CEs nasceram por esforço comunitário e associativo local. A cultura associativista encontrada em comunidades geradas por colonos de origem europeia também favoreceu o desenvolvimento do sistema cooperativista (COOPERS; LYBRAND, 1997).

Dessemelhante ao modelo desenvolvido no Sul e Sudeste, no nordeste, a maioria das cooperativas surgiu por estímulo das próprias concessionárias, com o intuito de servir como canalizadoras de recursos de programas de eletrificação rural (OLIVEIRA, 2001). De acordo com Oliveira (2001, p.99), essas “cooperativas-virtuais" são, muitas vezes, dirigidas por funcionários da própria concessionária. Na prática, atuam como prestadoras de serviços às concessionárias e não possuíam autonomia decisória e gerencial, nem programas próprios de eletrificação rural (COOPERS; LYBRAND, 1997).

Nesta perspectiva, estudo realizado por Pelegrini et al. (2004, p.2), explica que, as cooperativas criadas no nordeste, foram criadas pelas concessionárias "geralmente a rede de média tensão pertence às concessionárias, e as cooperativas detêm a propriedade e são responsáveis pelas redes de baixa tensão, pela medição e pelo relacionamento com o consumidor/cooperado." O modelo criado no Sul e Sudeste é diferente: foram criadas cooperativas que possuíam a propriedade e a gestão de toda a rede, de média e baixa tensão (PELEGRINI, 2004).

De acordo com Tendrih (1990) apud Pelegrini (2003, p.19), até a década de 1990, houve a expansão do número de CEs com o incentivo do Estado e até das concessionárias. Essa expansão ocorreu primordialmente pela facilidade na obtenção de recursos externos, pois "Os financiadores estrangeiros consideravam essa forma (cooperativismo) como a mais adequada à eletrificação rural". Para Tendrih (1990, p.67), "Este seria, mais um caso de 
tentativa de transposição de experiências bem sucedidas em outros países, para o Brasil."

Mas, partir da década de 90, as cooperativas ficaram à margem do setor elétrico. Pelegrini (2003, p.30) explica em sua tese de doutorado que a perplexidade do setor elétrico brasileiro, a partir dos anos 90, atingiu as CEs. As dificuldades financeiras, redução drástica de investimentos pelo governo, pouca vontade de fazer eletrificação rural, preços e tarifas altos, cobrança de importâncias indevidas, pretensamente justificadas pelo aspecto de serem cooperativas, aliado aos processos de privatização do setor, foram as principais situações que levaram a uma crise das CEs.
Segundo Pelegrini (2003), os financiamentos dos programas de eletrificação nesta época, estavam restritos às concessionárias estatais e as CEs, tinham as concessionárias de propriedade do Estado como suas adversárias existenciais.

Assim, o quadro atual de CEs, que na década de 80, foi de mais de 260 CEs, hoje é de 68 CEs. De acordo com a Confederação Nacional das Cooperativas de Infra-estrutura (INFRACOOP, 2012), das 68 (sessenta e oito) CEs, 65 (sessenta e cinco) são suas filiadas por meio de 6 (seis) federações estaduais. A tabela a seguir apresenta o nome da federação e a quantidade de cooperativas filiadas.

Tabela 1 - Cooperativas vinculadas à INFRACOOP

\begin{tabular}{|lcrc|}
\hline \multicolumn{1}{r}{ Feder açāo } & Cooper ativas & \multicolumn{1}{c|}{$\%$} & Estado \\
\hline FECOERGS & 15 & $23,08 \%$ & RS \\
FECOERPA & 7 & $10,77 \%$ & PR \\
FECOERESP & 16 & $24,62 \%$ & SP \\
FECOERMS & 3 & $4,62 \%$ & MS \\
FECOERUSC & 21 & $32,31 \%$ & SC \\
FECODERJ & 3 & $4,62 \%$ & RJ \\
\hline SOMA & 65 & $100 \%$ & \\
\hline
\end{tabular}

Fonte: Adequado (INFRACOOP, 2012)

Neste período foram inúmeras as CEs, que deixaram de desenvolver suas atividades, primordialmente as localizadas na região nordeste do Brasil.

\subsection{Cooperativas de eletrificação nos Estados Unidos}

Até a década de 30, nove em cada 10 famílias rurais americanas não possuiam eletrificação em suas residências. Pois nesta época as empresas de eletrificação não tinham interesse de atender as regiões mais distantes dos centros, pois demandavam valores expressivos de investimentos com pouco retorno dos valores investidos.

Assim, por meio de uma medida governamental, (Ordem Executiva ${ }^{\circ} 7.037$ de 11 de maio de 1935) o presidente americano Franklin D. Roosevelt, criou a Administração Rural de Eletrificação (REA) (a partir de ano de 1994 a REA passou a se denominar de Rural Utilities Service (RUS), vinculada ao Departamento de Agricultura dos EUA, mantendo os mesmos objetivos da REA). A RUS é uma agência do Departamento de Agricultura Americano responsável em financiar, com recursos públicos, as empresas dispostas a fornecer energia às propriedades rurais (REA, 2104). O incentivo governamental americano, era na forma de apoio técnico e financiamentos com juros subsidiados e prazos de 30 anos (TEIXEIRA, 1988).

De acordo com REA (2014), não demorou muito para que os vizinhos se unissem para criar cooperativas de eletrificação; pois as cooperativas poderiam obter financiamentos da REA para construir sistemas elétricos. Isso fez com que surgissem centenas de cooperativas de eletrificação (CEs), espalhadas por todo o território americano.

Pelegrini (2003) explica que, em fins da década de 40, quase toda a área rural americana estava eletrificada. No ano de 1953 , mais de $90 \%$ por cento das áreas rurais americanas tinham eletricidade. Atualmente, $99 \%$ por cento das áreas rurais do país têm serviço de energia elétrica, por meio de CEs. 
Tabela 2 - Períodos (décadas) em que surgiram as CEs, americanas

\begin{tabular}{|ccc|}
\hline Periodas/Anos & ne CEs criadas & $\%$ \\
\hline $1914=1930$ & 8 & $0,88 \%$ \\
$1931=1940$ & 619 & $68,40 \%$ \\
$1941=1950$ & 167 & $18,45 \%$ \\
$1951=1960$ & 11 & $1,22 \%$ \\
$1961=1970$ & 19 & $2,10 \%$ \\
$1971=1980$ & 16 & $1,77 \%$ \\
1981 a 1990 & 6 & $0,66 \%$ \\
1991 a 2000 & 44 & $4,86 \%$ \\
2000 a 2010 & 15 & $1,66 \%$ \\
\hline SOMA & 905 & $100,00 \%$ \\
\hline
\end{tabular}

Fonte: Adaptado de http://www.nreca.coop/wp-content/plugins/nreca-interactive-maps/coop-growth/index.html

Percebe-se pela tabela 2, que $86,85 \%$ das CEs americanas surgiram nas décadas de 30 e 40, logo após a edição da medida governamental.

As CEs americanas são representadas pela Associação Nacional das Cooperativas de Eletrificação (NRECA), fundada em 1942 na cidade de Arlington, Virginia. A NRECA une as cooperativas de geração, transmissão e distribuição de energia, e representa às 905 CEs, (840 CEs de distribuição de energia e 65 de geração e distribuição de energia). As CEs americanas atendem a um número aproximado de 42 milhões de consumidores de energia em 47 estados americanos (NRECA, 2014).

\section{Metodologia}

O presente estudo se caracteriza com uma pesquisa qualitativa e quanto aos objetivos a pesquisa é do tipo exploratória. A pesquisa exploratória é usada para desenvolver uma melhor compreensão sobre o assunto, ou também quando há pouco conhecimento acumulado e sistematizado (HAIR JR. et al. 2005; VERGARA, 1997).

De acordo com Gil (2005), na maioria dos casos a pesquisa exploratória assume a forma de pesquisa bibliográfica ou de estudo de caso. A pesquisa realizada se caracteriza exclusivamente como bibliográfica. Gil (2005), explica que a pesquisa bibliográfica é indispensável nos estudos históricos, pois possibilita conhecer os fatos passados.

Os materiais consultados para a realização da pesquisa bibliográfica foram os seguintes: livros, publicações periódicas, dissertações, teses, sites na rede mundial de computadores e impressos diversos.
As principais fontes bibliográficas consultadas foram: PINHO, 1966; SIMON, 2011; SOUTO; LOUREIRO, 1999; ANEEL, 2014; ICA,2011; COOPERS; LYBRAND, 1997; PELEGRINI,2003; RURAL ELECTRIFICATION ACT OF 1936; NRECA, 2014 e Legislações que tratam sobre o tema proposto.

Para alcançar os objetivos preestabelecidos da pesquisa, utilizou-se o método comparativo. Para Fachin (2001), o método comparativo consiste em investigar coisas ou fatos e explica-los segundo suas semelhanças e suas diferenças. O método comparativo se caracteriza por abordar duas séries de natureza análoga tomadas de meios sociais (...) a fim de detectar o que é comum a ambas (FACHIN, 2001).

Nesta perspectiva, após a leitura, análise e interpretação de diversas bibliografias, foi possível descrever sobre os principais aspectos relativos ao processo histórico das CEs do Brasil em relação às cooperativas americanas, apresentando seus pontos comuns e suas diferenças.

\section{Apresentação e análise dos Resultados}

Na sequência apresentam-se os resultados do estudo, contemplando um contexto histórico das CEs brasileiras em relação ao modelo americano, bem como a situação atual das CEs no Brasil, como permissionárias ou autorizadas de um serviço público.

A experiência americana, bem como em alguns países da Europa, fez surgir cooperativas de eletrificação rural em toda a América Latina, inclusive no 
Brasil. Antes, ainda na década de 20, já haviam sido realizadas as primeiras tentativas de se organizar a eletrificação por cooperativas. (PELEGRINI, 2003)

A primeira menção de um texto legal específico do setor elétrico sobre às cooperativas de eletrificação rural no Brasil, foi estabelecido pelo art. 154, inciso III do Decreto $n^{\circ}$ 41.019/57, que regulamenta o Código de Águas, como agentes atuantes no processo de expansão dos sistemas elétricos.

A menção das atividades a serem realizadas pelas (CEs), surgiu por meio do Decreto 1.033 de 22/05/62, que é o primeiro marco regulatório específico para as cooperativas de eletrificação rural do Brasil.

Este decreto veio a realizar uma ação comum do Direito, de transformar uma situação de fato em uma situação de direito, trazendo para a regulamentação do setor elétrico um agente existente, a cooperativa de eletrificação rural (PELEGRINI, RIBEIRO, PAZZINI; 2004).

Pelegrini (2004) explica que pelos decretos $n^{\circ}$ 41.019/57 e $\mathrm{n}^{\mathrm{o}} 1033 / 62$, ficou evidente que o campo de atuação das cooperativas, ficou tutelado pelo poder público e pelas concessionárias. "A intenção seria o fomento a cooperativas de eletrificação que, a medida que tivessem o mercado expandido, fossem absorvidas pelas concessionárias."

Isso demonstra o desinteresse dos governos do Brasil, em incentivar a expansão e consolidação do modelo de eletrificação rural por meio das CEs.

Situação oposta se constata no tratamento das CEs americanas, em relação às brasileiras. Enquanto as CEs americanas foram instituídas e consolidadas por políticas e incentivo governamentais de longo prazo, no caso das CEs brasileiras, as mesmas carecem de reconhecimento.

Pesquisa, realizada por Correia (1993), e citada por Pelegrini (2003, p.85), em sua tese de doutorado, explica que no ano de 1989, o Comitê de Distribuição - Codi - e, em 1990, o Comitê de Controle de Operações do Nordeste - CCON reuniram as concessionárias, para uma enquete sobre a situação da eletrificação rural, fazendo a todas elas as mesmas quase cem perguntas. Havia cinco perguntas que se relacionavam com as cooperativas de eletrificação rural, entre as quais:

Indagava-se: Elas existem? Atrapalham o desempenho dos circuitos da concessionária? Há uma política de incorporação das cooperativas de eletrificação rural?

Assim havia pouco reconhecimento do trabalho das cooperativas de eletrificação pelo governo e concessionárias.

Ressalta-se a resposta da CEMIG (Companhia Energética de Minas Gerais): Já havia incorporado 34 cooperativas, mas ainda restavam 4 (quatro) por incorporar. A Celg, também pretendia incorporar as cooperativas de sua área, e a Energipe tencionava excluí-las de qualquer programa novo de eletrificação rural. (CORREIA,1993; PELEGRINI, 2003).

De acordo com Simon (2011, p.55), “(...) a guerra, entre as concessionárias e as cooperativas de eletrificação, era baseada na absoluta falta de definição de competências, em nível federal e estadual e a incompreensão das concessionárias públicas."

\begin{abstract}
A eletrificação rural do Brasil tornou-se uma grande confusão institucional. Estabeleceu-se uma dualidade de competências e programas. Como as concessionárias estaduais acabam manipulando o poder concedente de maneira peculiar e circunstâncias próprias, a distribuição rural tornou-se palco de conflitos, divergências e luta pelo poder entre as diferentes concessionárias e as cooperativas de eletrificação rural" (RIBEIRO, 1993, p 36 $\underline{s s}$ ).
\end{abstract}

Estas situações levaram muitas CEs a partir da década de 90 a serem incorporadas as concessionárias e ao fechamento de muitas, o que ocasionou a diminuição do número delas, conforme se constata por meio da tabela 3 .

Com a reestruturação do setor elétrico brasileiro, iniciada a partir da década de 90 , tendo em vista a privatização das concessionárias de energia do governo, no ano 2005, foram intimadas pela ANEEL, 147 (cento e quarenta e sete) CEs, para se regularizar como agentes de um serviço público na condição de permissionárias ou autorizadas de um serviço público.

Por meio do quadro 3 apresenta-se a situação atual partir da abertura dos processos de regularização das CEs iniciados no ano de 2005. 
Tabela 3 - Quantidade de CE por estado nos anos de 1980, 2005 e 2012.

\begin{tabular}{|c|c|c|c|c|c|c|}
\hline $\begin{array}{c}\text { Unidade da } \\
\text { Federação da } \\
\text { Cooperativa }\end{array}$ & $\begin{array}{c}n^{0} \text { de cooperativas } \\
\text { em } 1980\end{array}$ & $\%$ & $\begin{array}{c}\mathbf{n}^{0} \text { de } \\
\text { cooperativas em } \\
2005(*)\end{array}$ & $\%$ & $\begin{array}{c}\mathbf{n}^{\mathbf{o}} \text { de } \\
\text { cooperativas em } \\
2012(* *)\end{array}$ & $\%$ \\
\hline Ceará & 13 & $5,00 \%$ & 12 & $8,16 \%$ & & \\
\hline Alagoas & 5 & $1,92 \%$ & & & & \\
\hline Goiás & 22 & $8,46 \%$ & 14 & $9,52 \%$ & & \\
\hline Distrito Federal & 1 & $0,38 \%$ & & & & \\
\hline Bahia & 14 & $5,38 \%$ & & & & \\
\hline Maranhão & 6 & $2,31 \%$ & 7 & $4,76 \%$ & & \\
\hline Mato Grosso & 2 & $0,77 \%$ & 1 & $0,68 \%$ & 1 & $1,47 \%$ \\
\hline Mato Grosso do Sul & 5 & $1,92 \%$ & 4 & $2,72 \%$ & 4 & $5,88 \%$ \\
\hline Minas Gerais & 31 & $11,92 \%$ & 4 & $2,72 \%$ & & \\
\hline Paraiba & 9 & $3,46 \%$ & 8 & $5,44 \%$ & & \\
\hline Pará & 1 & $0,38 \%$ & 1 & $0,68 \%$ & & \\
\hline Paraná & 21 & $8,08 \%$ & 7 & $4,76 \%$ & 7 & $10,29 \%$ \\
\hline Pernambuco & 19 & $7,31 \%$ & 12 & $8,16 \%$ & & \\
\hline Piaui & 7 & $2,69 \%$ & 8 & $5,44 \%$ & & \\
\hline Rio de Janeiro & 6 & $2,31 \%$ & 5 & $3,40 \%$ & 3 & $4,41 \%$ \\
\hline Rio Grande do Norte & 5 & $1,92 \%$ & 8 & $5,44 \%$ & & \\
\hline Rio Grande do Sul & 20 & $7,69 \%$ & 16 & $10,88 \%$ & 15 & $22,06 \%$ \\
\hline Rondônia & 0 & $0,00 \%$ & 1 & $0,68 \%$ & & \\
\hline Santa Catarina & 38 & $14,62 \%$ & 21 & $14,29 \%$ & 21 & $30,88 \%$ \\
\hline São Paulo & 33 & $12,69 \%$ & 17 & $11,56 \%$ & 16 & $23,53 \%$ \\
\hline Sergipe & 2 & $0,77 \%$ & 1 & $0,68 \%$ & 1 & $1,47 \%$ \\
\hline SOMA & 260 & $100,00 \%$ & 147 & $100,00 \%$ & 68 & $100,00 \%$ \\
\hline
\end{tabular}

Fonte: Adaptado de Avaliação do Cooperativismo no Brasil. (Pinho, 1981, p.75), (ANEEL, 2012) (*) Quadro demonstrativo da Situação dos Processos de Regularização das Cooperativas - SCT/ANEEL e (**) Número de cooperativas regularizadas e com processo em andamento de regularização como autorizadas ou permissionárias junto a ANEEL - SCT/ANEEL (2012)

Quadro 3 - Situação dos Processos de Regularização das CE

\begin{tabular}{|c|c|c|c|c|c|c|c|}
\hline \multirow{3}{*}{ Região } & \multirow{3}{*}{ Estado } & \multirow{3}{*}{$\begin{array}{c}\mathrm{n}^{\mathbf{o}} \mathrm{de} \\
\text { Cooperativas } \\
\text { no ano de } \\
2005 \\
\end{array}$} & \multicolumn{5}{|c|}{ SITUAÇÃO DAS COOPERATIVAS DE ELETRIFICAÇÃO EM 31/05/2012 } \\
\hline & & & \multicolumn{2}{|c|}{ Regularizadas } & \multicolumn{2}{|c|}{ Processos em andamento } & \multirow{2}{*}{$\begin{array}{l}\text { Pleito Indeferido/Ativo Transferido à } \\
\text { Concessionária e em transferência }\end{array}$} \\
\hline & & & Permissionárias & Autorizadas & Permissionárias & Autorizadas & \\
\hline \multirow{2}{*}{$\mathrm{N}$} & Rondônia & 1 & & & & & 1 - Indeferido \\
\hline & Para & 1 & & & & & 1 - Indeferido \\
\hline \multirow{7}{*}{$\mathrm{NE}$} & Piaui & 8 & & & & & 8 - Indeferidos \\
\hline & Maranhão & 7 & & & & & 7 - Indeferidos \\
\hline & Ceará & 12 & & & & & 12 - Indeferidos \\
\hline & Rio G. do Norte & 8 & & & & & 8 - Ativos Transferidos \\
\hline & Pernambuco & 12 & & & & & $\begin{array}{l}12 \text { - Em processo de Transf. para a } \\
\text { concessionária }\end{array}$ \\
\hline & Paraíba & 8 & & & & & 8 - Indeferidos \\
\hline & Sergipe & 1 & 1 & & & & \\
\hline \multirow{3}{*}{ SE } & Minas Gerais & 4 & & & & & 4 - Indeferidos \\
\hline & Rio de Janeiro & 5 & 1 & & 2 & & 2 - Atendimentos Transferidos \\
\hline & São Paulo & 17 & 10 & 3 & 2 & 1 & 1 - CER adquirida pela CPFL \\
\hline \multirow{3}{*}{$\mathrm{S}$} & Paraná & 7 & 1 & 3 & 1 & 2 & \\
\hline & Santa Catarina & 21 & 17 & & 4 & & \\
\hline & Rio G. do Sul & 16 & 8 & 2 & 5 & & 1 - CER incorporada pela CERVALE \\
\hline \multirow{3}{*}{$\mathrm{CO}$} & Mato Grosso & 1 & & & & 1 & \\
\hline & Mato G. Sul & 4 & & 4 & & & \\
\hline & Goiás & 14 & & & & & 14 - Ativos Transferidos á \\
\hline & TOTAL & \multirow{2}{*}{147} & 38 & 12 & 14 & 4 & $\begin{array}{r}99 \\
\end{array}$ \\
\hline Total p & or Situação & & 50 & & \multicolumn{2}{|l|}{18} & 79 \\
\hline
\end{tabular}

Fonte: Adaptado do quadro demonstrativo da situação dos processos de regularização das cooperativas. Superintendência de concessões e autorizações de transmissão e distribuição - SCT/ANEEL (2012). 
Denota-se por meio do quadro 3, que das 147 (cento e quarenta e sete) CEs, reconhecidas pela Aneel no ano de 2005, 50 (cinquenta) já estão regularizadas, sendo 38 (trinta e oito) como permissionárias e 12 (doze) como autorizadas, 18 (dezoito) cooperativas estão com processo de regularização em andamento, sendo 14 (quatorze) com processo para se tornar permissionária e 4 (quatro) com processo para se tornar autorizada.

De acordo com a ANEEL (2012), as cooperativas que não se enquadravam no disposto do Artigo 23 da lei $n^{\circ}$ 9.074/1995 e/ou que não atenderam os requisitos da Resolução/ANEEL ${ }^{\circ} 12$ de 23 de janeiro de 2002 tiveram seus processos de regularização indeferidos.

Nesses casos, a concessionária local assume a distribuição de energia elétrica que antes era feita pela CEs. Destarte do ano de 2005 até maio de 2012, foram 79 (setenta e nove) as CEs que acabaram desativando suas atividades de distribuição e comercialização de energia, com a transferência de seus ativos as concessionárias locais. Das 68 (sessenta e oito) CEs, remanescentes, 65 (sessenta e cinco) são ligadas à INFRACOOP (Sistema INFRACOOP), possuem 3733 empregados, 535.000 associados e desenvolvem suas atividades na geração e (ou) distribuição e comercialização de energia para 626 municípios de 6 (seis) Estados do Brasil, sendo que 22 cooperativas atuam na geração e distribuição de energia e 43 atuam somente na distribuição e comercialização de energia (INFRACOOP, 2012).

Para a OCESP (2015), o Brasil possui aproximadamente 5.200.000 propriedades rurais, destas apenas $21 \%$ usufruem dos benefícios da energia elétrica. São aproximadamente 1.120 .000 propriedades rurais eletrificadas, 420.000 das quais pelo sistema cooperativista, sendo que $90 \%$ dos recursos aplicados partiram dos próprios cooperados.

Infere-se, em muitas propriedades rurais brasileiras, que ainda não possuem eletrificação, as mesmas poderiam ser atendidas por meio de programas de eletrificação por meio de Cooperativas de Eletrificação, como ocorrido no modelo americano, a partir da década de 30 .

Por outro lado, nos Estados Unidos as 905 (novecentos e cinco) CEs distribuem atualmente energia para 2500 municípios americanos, o que corresponde a $12 \%$ dos medidores, são proprietárias de 3,7 milhões de quilômetros de redes de distribuição, equivalente a $43 \%$ do total das redes americanas, cobrindo três quartos do território americano. As CEs americanas possuem em média 11.500 consumidores de energia por cooperativa, comercializam $10 \%$ de toda a energia consumida nos EUA. No que se refere a geração de energia as CEs americanas produzem 5\% da energia a cada ano e possuem 60.000 funcionários. (NRECA, 2014).

No Brasil, a partir da regulamentação imposta na metade da década de 95, as CEs remanescentes, passaram a ser classificadas junto ao agente regulador (ANEEL) como permissionárias ou autorizadas de um serviço público.

De acordo com PELEGRINI et al. (2004), na modalidade de permissionária, a cooperativa deve assinar um contrato de adesão à permissão, onde se submete às normas do poder concedente em relação às tarifas e prestação do serviço. Em contrapartida, é garantido o equilíbrio econômico-financeiro da permissão.

Para às permissionárias é necessária à definição de uma área de atuação para fins de regularização, para a qual a cooperativa possui as prerrogativas e a obrigação de prestar o serviço de distribuição de modo exclusivo (PELEGRINI et al, 2004). Com área demarcada (área de abrangência garantida) as cooperativas permissionárias se obrigam a atender a um público urbano ou rural, (público indistinto) com tarifas homologadas pela ANEEL, sejam cooperados (associados) ou terceiros.

O tratamento estabelecido as CEs brasileiras em termos de qualidade de atendimento ao consumidor, eficiência, é o mesmo exigido às 65 (sessenta e cinco) grandes concessionárias distribuidoras de eletrificação que atuam no Brasil.

Neste contexto as CEs, passam a se defrontar com inúmeros desafios, entre os quais: a) operar na distribuição de energia, atendendo aos mesmos padrões de qualidade das grandes concessionárias; b) serem eficientes em seus processos, pois com áreas de atuação na distribuição de energia delimitada, ficam limitadas a obter ganhos de escala; c) As concessionárias são as distribuidoras de energia para as CEs, com subsídios.

Destarte, os aspectos inerentes aos princípios norteadores do cooperativismo, desenvolvidos pelas CEs, brasileiras, em suas regiões de abrangências, 
são pouco reconhecidos e de importância pelos reguladores e governos.

As principais vantagens das CEs, em relação as grandes concessionárias, são: a) exercer suas atividades, de acordo com os princípios cooperativos; b) possuir maior agilidade no atendimento das ocorrências junto aos seus associados; c) atuar como agente de desenvolvimento na economia dos municípios das regiões de atuação; d) obter maior eficiência nos processos da distribuição de energia, (apontamentos dos medidores pelos associados); e) facilidade de mobilização dos associados (consumidores de energia) em programas de eficiência energética; (redução de perdas de energia etc), f) desenvolvimento de programas socioambientais etc.

Para as CEs americanas, seu desenvolvimento e atuação foram alicerçados em programas de governo, que perduram até os dias atuais. Nesta perspectiva, legitimizou-se o cooperativismo, como o modelo para a implantação da eletrificação rural americana.

\section{Conclusões}

O modelo de eletrificação rural por meio das CEs, que foi fundamental para o desenvolvimento do setor rural americano a partir da década de 30 , não seguiu os mesmos caminhos no Brasil.

A inexistência de políticas de eletrificação de longo prazo com foco nas CEs, não proporcionou o crescimento do setor, no Brasil. Assim, o modelo de eletrificação rural por meio das CEs, desenolveu-se de forma enviesado com as concessionárias públicas.

A partir da metade da década de 90, o interesse por áreas atendidas pelas CEs, foi ainda maior, pois o setor começou a ser gerido em grande parte no Brasil pelas concessionárias privadas, que buscavam obter maior escala na distribuição de energia.

Os problemas que existiam no surgimento das CEs, no Brasil, entre os quais a indefinição de competências, a insegurança jurídica, no que se refere as regras do setor, a competição por áreas de atendimento de energia com as grandes concessionárias antes públicas e agora privatizadas, o tratamento de forma igual as grandes concessionárias, são alguns dos pontos que ainda perduram até os dias atuais.

Por fim, denota-se que o crescimento do setor rural americano deu-se prioritariamente pela entrada de energia elétrica na década de 30 . O programa de incentivo governamental, com foco em investimento na eletrificação foi o motor que acelerou a expansão da eletrificação rural americana. No Brasil, muitas regiões ainda carecem de eletrificação rural, que poderiam ser realizadas, por incentivo governamental as CEs.

\section{Referências}

ANEEL - Agência Nacional de Energia Elétrica. Disponível no Saite da ANEEL: http://www.aneel.gov.br/. Acessado em 04 de jun.2012.

ANEEL - Agência Nacional de Energia Elétrica.. Ministério de Minas e Energia (MME). Prestação de contas ordinária anual. Relatório de Gestão do Exercício de 2010. Brasília. Março/2011. Disponível em:http://www.aneel.gov.br/arquivos/PDF/Relat \%C3\%B3rio_de_Gest\%C3\%A3o_2010_ANEEL _V1\%20\%282\%29.pdf. Acessado em 04 de jun. 2012.

BRASIL, Lei no 5764/71 de 16 de dezembro de 1971. Define a política nacional de cooperativismo, institui o regime jurídico das cooperativas, e dá outras providências. Disponível em: http://www.planalto.gov.br/ccivil_03/leis/L5764. htm Acessado em 09 de fev. 2012.

BRASIL, Decreto $\mathrm{n}^{\circ} 6160$ de 20 de julho de 2007. Regulamenta os $\S \S 1^{\circ}$ e $2^{-}$do art. 23 da Lei $n^{0}$ 9.074, de 7 de julho de 1995, com vistas à regularização das cooperativas de eletrificação rural como permissionárias de serviço público de distribuição de energia elétrica, e dá outras providências. Disponível em: http://www.planalto.gov.br/ccivil_03/_Ato2007 2010/2007/Decreto/D6160.htm. Acessado em 05 de mai. 2012.

BRASIL, Lei no 9.074, de 7 de julho de 1995. Estabelece normas para outorga e prorrogações das concessões e permissões de serviços públicos e dá outras providências. Disponível em: http://www.planalto.gov.br/ccivil_03/leis/L9074 cons.htm.Acessado em 10 de jun. 2012. 
BRASIL, Decreto no. 41.019, de 26 de fevereiro de 1957. Regulamenta o Código de Águas. Brasília, DF, 1957.

BRASIL, Decreto no. 1.033, de 22 de maio de 1962. Brasília, DF, 1962.

COOPERS \& LYBRAND. Projeto de Restruturação do Setor elétrico brasileiro: Etapa VI - Cooperativas de eletrificação rural (minu-

ta).novembro de 1997.

COOPERS \& LYBRAND. Projeto de restruturação do setor elétrico brasileiro: cooperativas de eletrificação rural. Relatório VI-2, Ministério de Minas e Energia / Eletrobrás. Brasília, 1997.

CORREIA, J. S. S. Eletrificação rural de baixo custo: avaliação e prática. Dissertação (mestrado). São Paulo, 1993, 242 p. Escola Politécnica da Universidade de São Paulo.

ETGETO, A.A., SILVA, C.G. B., VICENTE, F.C., GIROTTO, M.W., MIRANDA, I.T.P. Os Princípios do cooperativismo e as cooperativas de crédito no Brasil. Maringá Management:Revista de Ciências Empresariais, v. 2, n.1, p. 7-19, jan. /jun. 2005

FACHIN, O. Fundamentos de metodologia. 3. Ed. São Paulo: Saraiva, 2001.

FECOERGS - Federação das cooperativas de eletrificação do Estado do Rio Grande do Sul. http://www.fecoergs.com.br/. Acessado em 15 de jan. 2011.

FUGIMOTO, S.K., A universalização do serviço de energia elétrica acesso e uso contínuo. Dissertação apresentada à escola Politécnica da Universidade de São Paulo para a obtenção do título de mestre em Engenharia. São Paulo: 2005.

GIL, A.C. Como elaborar projetos e pesquisa. $4^{\mathrm{a}} \mathrm{ed}$. São Paulo: Atlas; 2005.

HAIR, JR. J.F., BABIN, B., MONEY, A.H., SAMOUEL, P. Fundamentos de métodos de pesquisa em administração. Porto Alegre: Bookman, 2005.
ICA - Aliança Cooperativa Internacional Disponível em: http://www.ica.coop/al-ica/ Acessado em 15 de jan. 2011.

NRECA. História das Cooperativas de Eletrificação. Disponível em: http://www.nreca.coop/ Acessado em 19 de jun. 2014.

OCB - Organização das Cooperativas Brasileiras.

Disponível:

http://www.brasilcooperativo.coop.br/site/ocb/in dex.asp?CodIdioma=1. Acesso em 12 de nov. 2011.

OCESP. Portal do Cooperativismo Disponível em: OCESP http://www.portaldocooperativismo.org.br/. Acessado em 19 de jun. 2015.

OLIVEIRA, L.C. Perspectivas para a eletrificação rural no novo cenário econômico -institucional do setor elétrico brasileiro.2001.UFRJ, Rio de Janeiro, 2001.Tese de Doutorado. Universidade Federal do Rio de Janeiro. COPPE. 2001. Disponível:

http://www.ppe.ufrj.br/ppe/porduction/tesis/lcoli veira.pdf. Acessado em 15 de jan. 2011.

PASIN, D. R. Contexto das cooperativas de eletrificação no Brasil. Sistema OCB.

10/2013.Disponívelem:http://www.aciamericas.c oop/IMG/pdf/seminario_servicios_publicos_roq ue.pdf. Acessado em 24 de jan. 2014.

PELEGRINI, M. A., RIBEIRO, F. S. and. ALVES, H. As cooperativas de eletrificação rural no novo cenário do setor elétrico. In: ENCONTRO DE ENERGIA NO MEIO RURAL, 5., 2004, Campinas. Proceedings online... Avaliable from: <http://www.porceedings.scielo.br/scielo.p hp?script=sci_arttext\&pid=MSC0000000022004 $000100017 \& \operatorname{lng}=\mathrm{en} \& \mathrm{nrm}=\mathrm{abn}>$. Acessado em 15 de jan. 2012.

PELEGRINI, M.A. Regulação das cooperativas de eletrificação rural. 2003. Tese (Doutorado em Engenharia) - Escola Politécnica, Universidade de São Paulo. São Paulo. 2003.

PINHO, D.B. Os princípios da aliança cooperativa Internacional (ACI). ITCP/USP/ Incubadora tec- 
nológica. Publicação em 1995. Disponível em: www.itcp.usp.br/drupal/node/209. Acessado em 02 de mar. 2012.

PINHO, D.B. Economia e cooperativismo. São Paulo: Saraiva, 1977.

PINHO, D.B. O que é cooperativismo. São Paulo: Coleção Buriti, 1966.

RIBEIRO, F.S. Eletrificação rural de baixo custo. São Paulo, junho de 1993. 157p. Tese (Livre Docência) - Escola Politécnica, Universidade de São Paulo.

ROSSET, G. C., LORENZI, J., MAROSO, L., SANTOS, D.M., NARDI, V. A regularização da cooperativa regional de eletrificação rural do alto Uruguai. Creral, como agente prestador do serviço público de distribuição de energia elétrica e suas vantagens e desvantagens.Revista de Administração e Ciências Contábeis do IDEAU, Vol.4.n.8jan/jun/2009.

Rural Electrification Act of 1936. The Rural Electrification Act of 1936 was intended to light the nation by supplying the infrastructure and funding to electrify isolated U.S. farms. May 20, 1936. [S. 3483.] [Public, No. 605.].Disponível: http://www.ccrh.org/comm/moses/primary/electr if.html. Acessado em 23 de jan. 2014.

SANTOS, A; GOUVEIA, F.H.C., VIEIRA., P.S. Contabilidade das Sociedades Cooperativas: Aspectos gerais e prestação de contas. São Paulo: Atlas. 2008.

SAITE: http://www.nreca.coop/ Saite: http://www.nreca.coop/wpcontent/plugins/nreca-interactive-maps/coopgrowth/index.html. Acessado em 23.jan. 2012.

SESCOOP/OCB. Relatório da Gerência de Monitoramento - Março 2012 - "Panorama do Cooperativismo Brasileiro - ano 2011.Disponível em: http://www.ocb.org.br/gerenciador/ba/arquivos/p anorama_do_cooperativismo_brasileiro__2011.pdf. Acessado em 12 de dez. 2012.
SESCOOP/OCB. Panorama nacional do cooperativismo. 2013. / CNCOOP-OCB-SESCOOP. 2014. Disponível em: http://www.ocb.org.br/ Acessado em 22 de jun. 2015.

SIMON, C. A revolução silenciosa. A saga da eletrificação rural cooperativada do RS. Porto Alegre: Sescoop. RS, 2011.

SOUTO, C.F., LOUREIRO, G. K. O novo modelo do setor elétrico brasileiro e as cooperativas de eletrificação rural. $1^{a}$ ed. Porto Alegre: Livraria Advogado. Editora, 1999.

TEIXEIRA, N. Eletrificação rural simplificada: sistema monofilar com retorno por terra - MRT. Rio de Janeiro, BNDES, 1988. (Cadernos FINSOCIAL n 8).

TENDRIH, L. Experiências com sistemas de eletrificação rural de baixo custo: uma análise dos impactos socioeconômicos. Dissertação (Mestrado) Universidade Federal Rural do Rio de Janeiro. Itaguaí, Rio de Janeiro, junho de 1990.

VERGARA, S.C. Projetos e Relatórios de pesquisa em administração. São Paulo: Atlas, 1997.

YADOO, A., CRUICKSHANK, H. The value of cooperatives in rural electrification. Energy Policy (2010), doi:10.1016/j.enpol.2010.01.031. Disponível em: http://indiaenvironmentportal.org.in/files/Energy \%20Policy.pdf. Acessado em 23 de jan. 2014. 